\title{
Detecting changes in Labrador Sea Water through a water mass analysis of BATS data
}

\section{A. Henry-Edwards and M. Tomczak}

School of Chemistry Physics and Earth Sciences, Flinders University of South Australia, GPO Box 2100, Adelaide SA 5001, Australia

Received: 24 June 2005 - Published in Ocean Sci. Discuss.: 30 August 2005

Revised: 28 November 2005 - Accepted: 28 February 2006 - Published: 8 March 2006

\begin{abstract}
A new water mass analysis technique is used to analyse the BATS oceanographic data set in the Sargasso Sea of 1988-1998 for changes in Labrador Sea Water (LSW) properties. The technique is based on a sequential quadratic programming method and requires careful definition of constraints to produce reliable results. Variations in LSW temperature and salinity observed in the Labrador Sea are used to define the constraints. It is shown that to minimize the residuals while matching the observed temperature and salinity changes in the source region the nitrate concentration in the Labrador Sea has to be allowed to vary as well. It is concluded that during the period of investigation nitrate underwent significant variations in the Labrador Sea.
\end{abstract}

\section{Introduction}

The Bermuda Atlantic Time-series Study (BATS), a project of the Bermuda Biological Station for Research (BBSR) and the Centre for Integrated Ocean Observations (CINTOO), has been producing high quality hydrographic data on a monthly basis since 1954 and now represents one of the best long-term oceanographic time series available. The study was primarily set up to investigate the biogeochemistry of the Sargasso Sea and its relation to climate variations (Steinberg et al., 2001). Consequently, much of the research done into the BATS data set concentrated on the upper few hundred metres (e.g. Anderson and Pondaven, 2003; Babiker et al., 2004; DuRand et al., 2001; Hood et al., 2001).

Work at the BATS site has contributed greatly to our understanding of nutrient processes in the upper levels of the ocean (Steinberg et al., 2001). In particular, our understanding of nutrient behaviour under different atmospheric conditions has been greatly improved. Hood et al. (2001) sug-

Correspondence to: $\mathrm{M}$. Tomczak

(matthias.tomczak@flinders.edu.au) gested that interannual fluctuations in $\mathrm{N}_{2}$ fixation might be linked to climate fluctuations over the North Atlantic, in particular to the North Atlantic Oscillation. Babiker et al. (2004) suggested a link with the direction of the prevailing winds over the Sargasso Sea.

There has been some work performed on the BATS data set looking at the deeper water properties and the hydrographic history. Joyce and Robbins (1996) suggested that a cooling in the deep layers of the BATS data might be linked to earlier cooling in the Labrador Sea. Curry and McCartney (1996) also suggested this scenario and gave a transit time of approximately six years.

In this paper we concentrate on the depth range 900 $1300 \mathrm{~m}$ and investigate the question whether it is possible to link variations in hydrographic properties observed at the BATS location to variations of hydrographic properties in water mass formation regions at significant distance from the observation site in a quantitative manner. We use a new water mass analysis technique, called Time Resolving Optimum Multi-Parameter (TROMP) analysis, for that purpose. The method requires observations of temperature, salinity, oxygen and nutrients. Sample collection for nutrient analysis was only taken up at the BATS site in 1988, so our analysis covers the ten year period 1988-1998.

\section{Data and method}

TROMP analysis was developed as an extension of classical OMP analysis (Tomczak, 1981) when a previous application of OMP analysis to the BATS dataset (Leffanue and Tomczak, 2005) indicated the disappearance of LSW at the BATS location during 1995-1997. The apparent disappearance was accompanied by a significant increase of the residual error. This led Leffanue and Tomczak to suggest that the disappearance of LSW was an artefact of the method, produced

Published by Copernicus GmbH on behalf of the European Geosciences Union. 

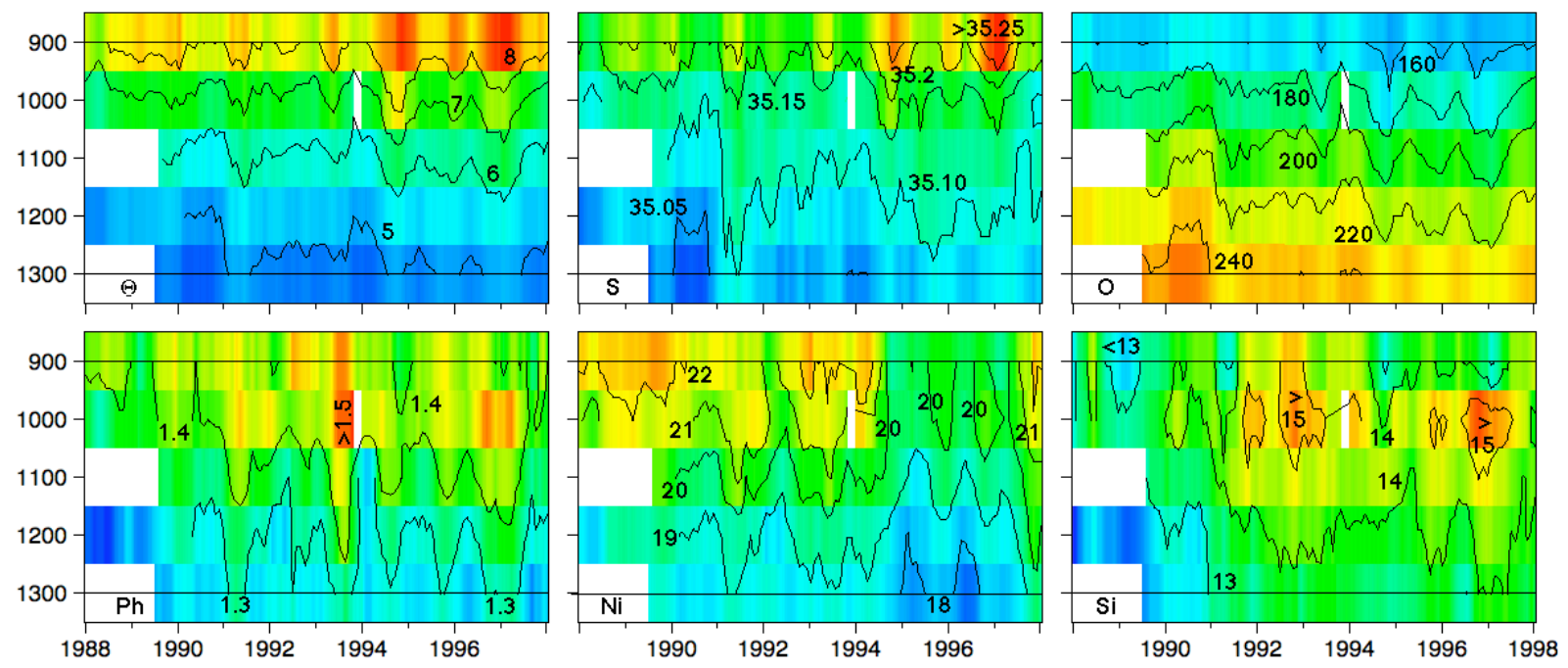

Fig. 1. Potential temperature $\Theta\left({ }^{\circ} \mathrm{C}\right)$, salinity $\mathrm{S}$, oxygen $\mathrm{O}(\mu \mathrm{mol} / \mathrm{l})$ and nutrients $\mathrm{Ph}, \mathrm{Ni}$ and $\mathrm{Si}(\mu \mathrm{mol} / \mathrm{l})$ at the BATS station for the depth range $900-1300 \mathrm{~m}$ after data preparation as described in the text. The resolution in the vertical (100 $\mathrm{m}$ intervals) is indicated by the coloured boxes. Resolution in time (weekly) can be judged from the interpolated contours.

by changes of LSW source water properties that cannot be accounted for in the OMP analysis.

A detailed description of TROMP analysis is given in Henry-Edwards and Tomczak (2006). To apply TROMP analysis to the BATS data, the data set had to be fitted to a uniform grid in space and time. Outliers in the BATS time series were removed, and the measurements were averaged into five vertical bins of $100 \mathrm{~m}$ thickness, starting from 850 $950 \mathrm{~m}$ for the uppermost layer to $1250-1350 \mathrm{~m}$ for the lowest layer. The time step was defined by the sampling interval (1 month). A five-month running mean was applied to the time series in order to filter short-term variations from the BATS data.

Tests of the TROMP analysis during its development and theoretical considerations with regard to the sequential programming technique used suggested that the method achieves the most reliable results if any changes of source water mass properties are small and evolve slowly in time. To meet that requirement the data sampling rate was increased from monthly to weekly by linear interpolation.

Figure 1 shows the resulting BATS data as used in the TROMP analysis. It is worth noting the level of variation in the nutrient data; nitrate concentrations in particular decrease at all depths during the period 1994-1997 when LSW disappeared in the analysis of Leffanue and Tomczak (2005). At the same time, the salinity concentration is increasing, and similar though smaller variations in the other water properties are taking place.

The investigation followed the conclusions of HenryEdwards and Tomczak (2006), who suggested the following sequence of steps:
Step 1: a series of TROMP analyses in which one source water property is allowed to vary across all source water types simultaneously, while all other source water properties are kept constant.

Step 2: inspection of the resulting error fields and analysis output, to identify source water properties which may have varied during the analysis period.

Step 3: a targeted TROMP analysis in which variations are restricted to the source water properties and SWTs identified as likely to have varied.

The constrained minimization method that underlies TROMP analysis has an unlimited number of solutions, and additional sources of information are required to provide guidance towards the most acceptable scenario. We used the temperature and salinity documented in Dickson et al. (1996) for the period 1982/83-1991/92 (Fig. 2) as a guide for the time evolution of LSW temperature and salinity. Additional guidance came from the results of Leffanue and Tomczak (2005), who gave LSW contributions of approximately $40 \%$ in the depth ranges 1100 to $1300 \mathrm{~m}$ at times when LSW was not absent from their analysis altogether. Assuming that LSW was still present but with different source water properties, it seems reasonable to expect that the volumetric contribution of LSW to water samples collected at the BATS site should remain close to $40 \%$ throughout the entire time period. Any TROMP analysis result that did not satisfy this requirement was thus deemed unrealistic.

Four source water types were included in the analysis of the depth range 900-1300 $\mathrm{m}$. These were upper and lower Western North Atlantic Central Water (WNACW), Iceland- 
Table 1. Source water definitions used in the BATS data analysis. Temperatures are in ${ }^{\circ} \mathrm{C}$, oxygen and nutrient data in $\mu \mathrm{mol} / \mathrm{L}$.

\begin{tabular}{lcccccc}
\hline Water Type & potential temperature & salinity & oxygen & phosphate & nitrate & silicate \\
\hline WNACW (upper) & 18.9 & 36.6 & 190.0 & 0.25 & 6.0 & 2.0 \\
WNACW (lower) & 9.40 & 35.1 & 135.0 & 1.70 & 24.0 & 15.0 \\
LSW & 3.165 & 34.832 & 305.0 & 1.09 & 16.4 & 9.1 \\
ISOW & 3.060 & 34.970 & 280.0 & 1.12 & 17.0 & 14.6 \\
\hline
\end{tabular}

Table 2. Parameter weights given by Leffanue and Tomczak (2005). All parameters are non-dimensionalised by dividing through the difference between the largest and smallest corresponding parameter values from Table 1, and all weights are non-dimensional.

\begin{tabular}{ccccccc}
\hline $\begin{array}{c}\text { potential } \\
\text { temperature }\end{array}$ & salinity & oxygen & phosphat & nitrate & silicate & $\begin{array}{c}\text { mass } \\
\text { conservation }\end{array}$ \\
\hline 271 & 126 & 30 & 4 & 32 & 10 & 271 \\
\hline
\end{tabular}

Scotland Overflow Water (ISOW) and Labrador Sea Water (LSW). The source definitions, taken from Leffanue and Tomczak (2005), are given in Table 1. OMP analysis of the BATS data set showed that in the depth range of interest, relative contributions for upper WNACW are low and generally less than $10 \%$. Application of TROMP analysis to simulated data showed that source water type variations are only recognized reliably if the water mass in question contributes significantly to the water sample. Therefore, though upper WNACW is still present and its contribution cannot be ignored, its water properties were not considered as possible variables but were kept constant throughout the analysis.

\section{Results}

A large number of TROMP analysis runs were performed for step 1 of the analysis. In each run a single source property was defined as a variable for the analysis and allowed to vary in all source water masses. The error fields generated in this way were not as clear as those generated for the simulated data sets in Henry-Edwards and Tomczak (2006).

Figures 3 and 4 show examples of runs from step 1 of the analysis and demonstrate what can be learnt from an ensemble of runs ( tribution of LSW decreases rapidly during the first two years and remains low during the remainder of the investigation period. It falls below 30\% during most of the time at the $900 \mathrm{~m}$ level and on several occasions at the $1000 \mathrm{~m}$ level. Through our experience with the TROMP analysis, we have found that if a water mass contributes less than a third of the measured sample, the results are usually unreliable. We therefore excluded data from the $900 \mathrm{~m}$ and $1000 \mathrm{~m}$ levels from further consideration in the analysis.

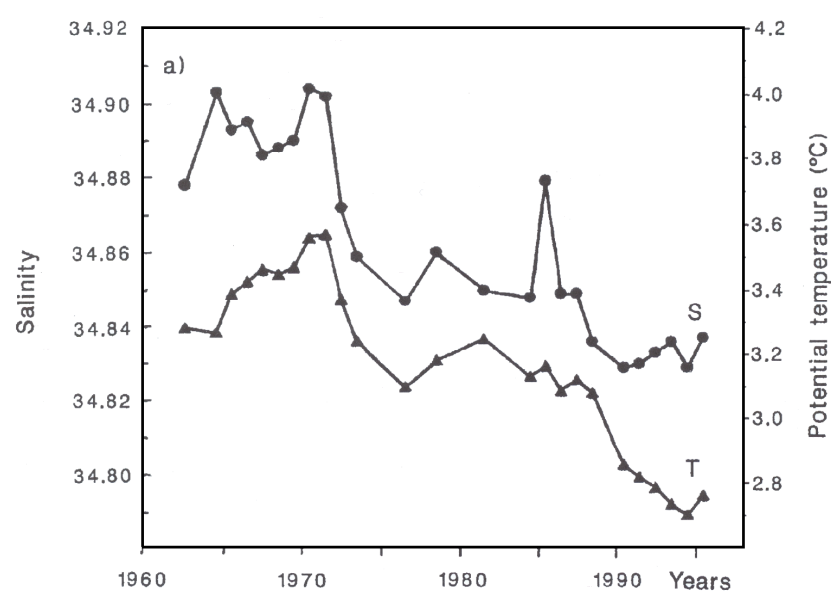

Fig. 2. Time development of LSW potential temperature and salinity for 1960-1995. From Dickson et al. (1996).

The results for the $1100 \mathrm{~m}, 1200 \mathrm{~m}$ and $1300 \mathrm{~m}$ levels generally follow the same trend in time but differ quantitatively. The variations of LSW potential temperature and salinity are much larger than observed and are certainly unrealistic. Comparison of Fig. 3 with Fig. 4 also shows that the quantitative result is quite dependent on the weights used. Leffanue and Tomczak (2004) derived their weights (Table 2) in the standard manner for OMP analysis to reflect the measurement accuracy and spread between water masses of each parameter. In a TROMP analysis weights play quite a different role; they influence the search direction of the line search procedure in the quadratic optimisation (Henry-Edwards and Tomczak, 2006), and there is no objective rule that determines their choice. We performed the analysis with numerous weightings, ranging from those of Leffane and Tomczak (2005) to uniform weights. Our final choice of weights (those 

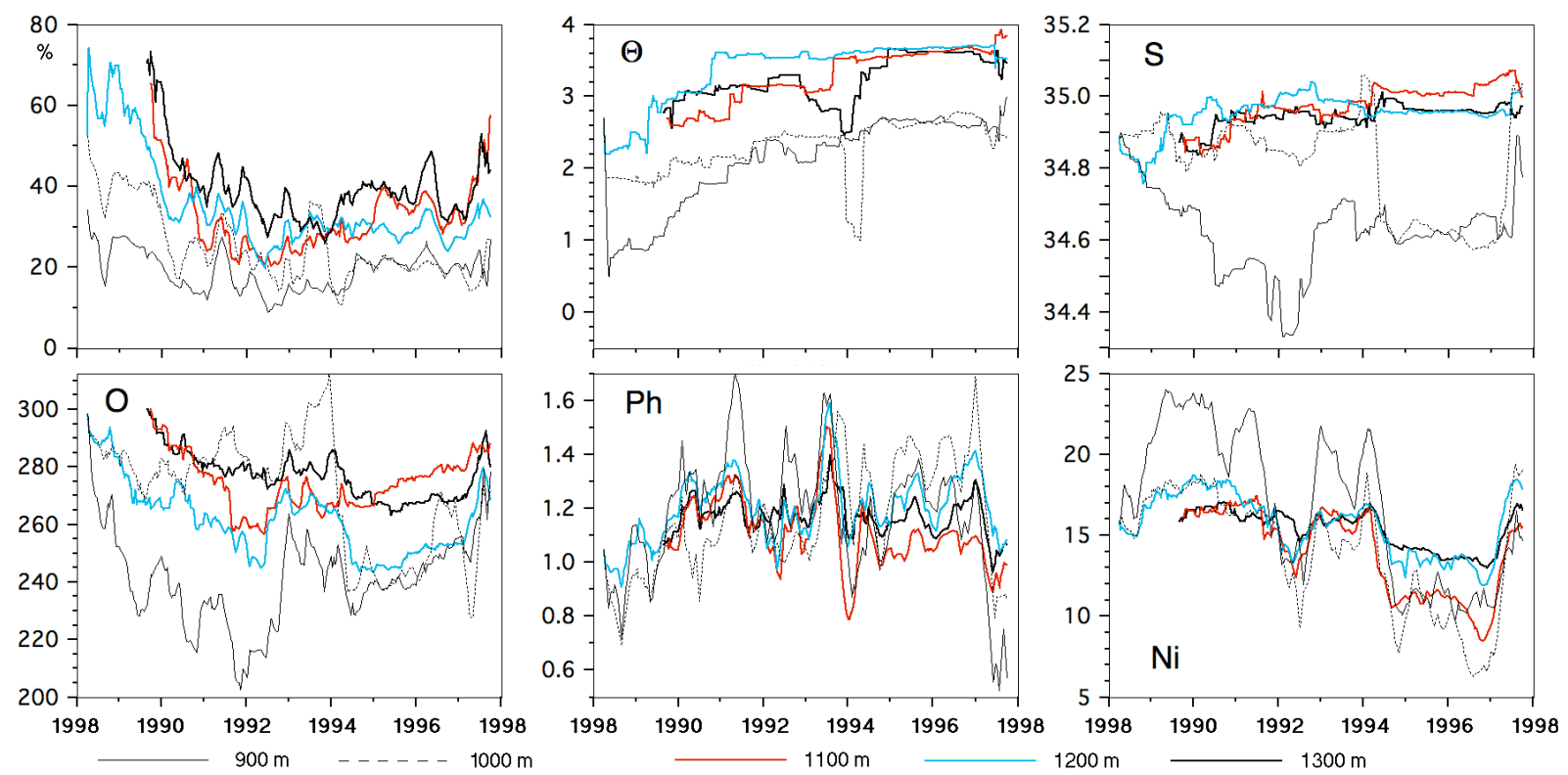

Fig. 3. Time development of the relative LSW contribution to the water samples and of the LSW source water properties potential temperature $\Theta\left({ }^{\circ} \mathrm{C}\right)$, salinity $\mathrm{S}$, oxygen $\mathrm{O}(\mu \mathrm{mol} / \mathrm{L})$, phosphate $\mathrm{Ph}(\mu \mathrm{mol} / \mathrm{L})$ and nitrate $\mathrm{Ni}(\mu \mathrm{mol} / \mathrm{L})$ if one source water property is varied in all source water types. Weights from Leffanue and Tomczak (2004).
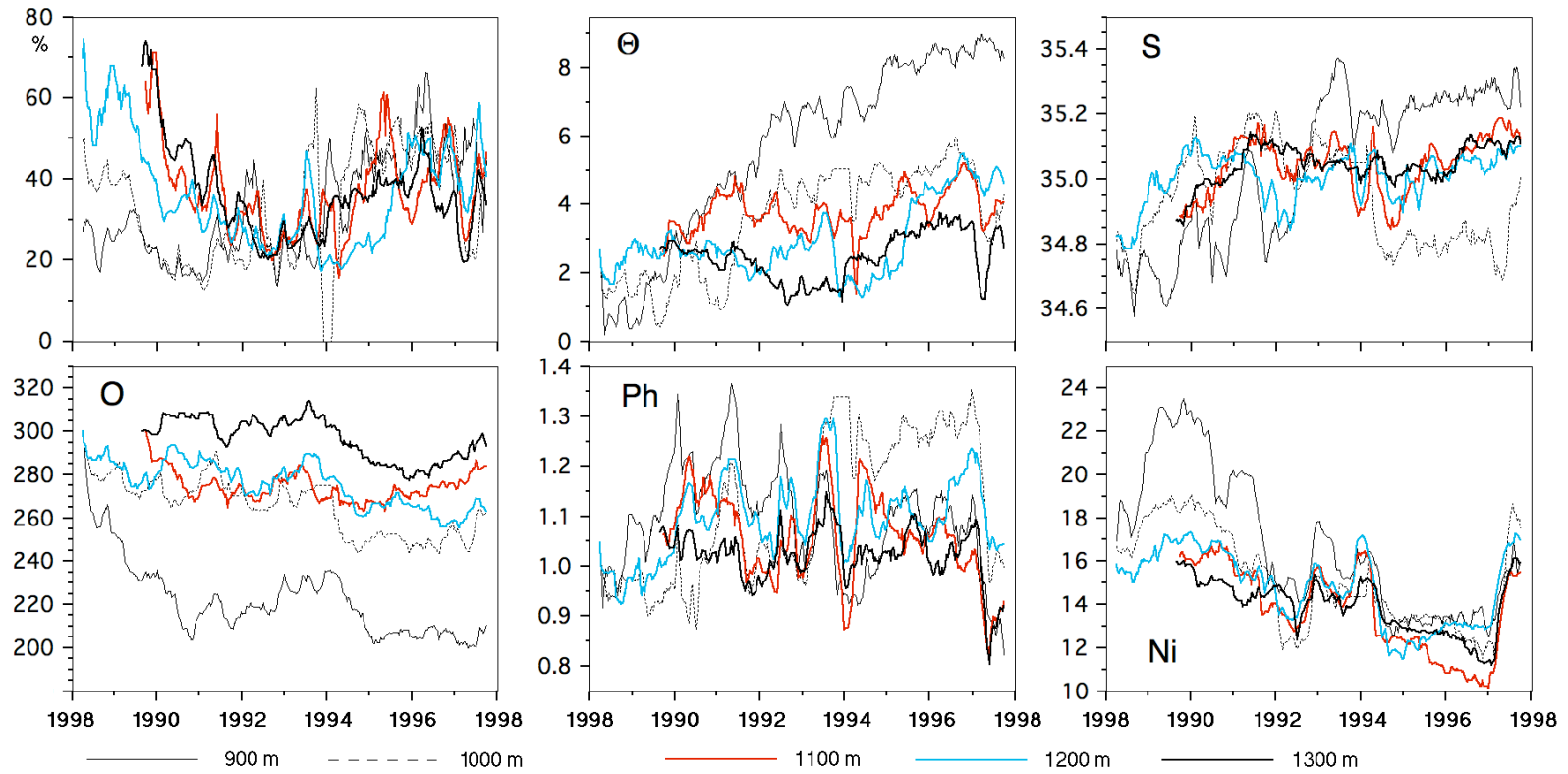

Fig. 4. As Fig. 3, but with uniform weights.

of Leffanue and Tomczak, 2005) was determined by the quality of the result as outlined below.

The insight gained from the runs shown in Figs. 3 and 4 as well as many other runs determined the conditions for step 3 of the analysis. LSW temperature and salinity were selected as variables, based on our knowledge from Dickson et al. (1996). It was also noted that the nitrate concentration showed a consistent decrease over time in all runs regard- less of the chosen weights (compare Figs. 3 and 4), while the other nutrients and oxygen behaved erratically and did not show clear trends. Nitrate was therefore included as a variable in the analysis, while oxygen, phosphate and silicate concentrations were kept as constants.

An interesting consequence of this is the implicit assumption that the Redfield ratio varied significantly in the Labrador Sea during the investigation period. To gain 

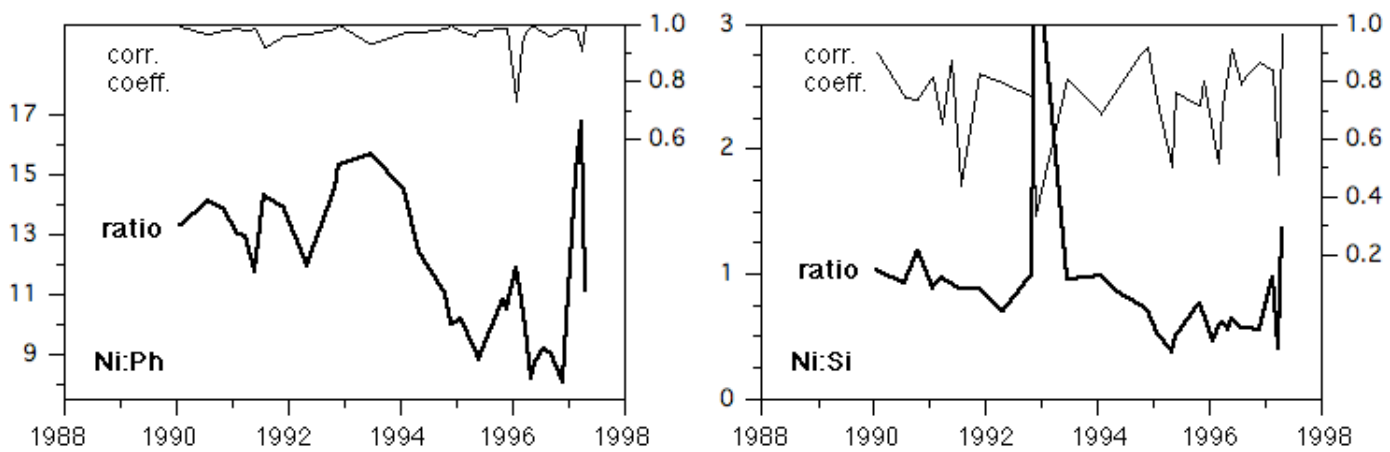

Fig. 5. Time variation of Redfield ratios (heavy lines) in the BATS data depth range 700-1600 m and associated correlation coefficients (thin lines).
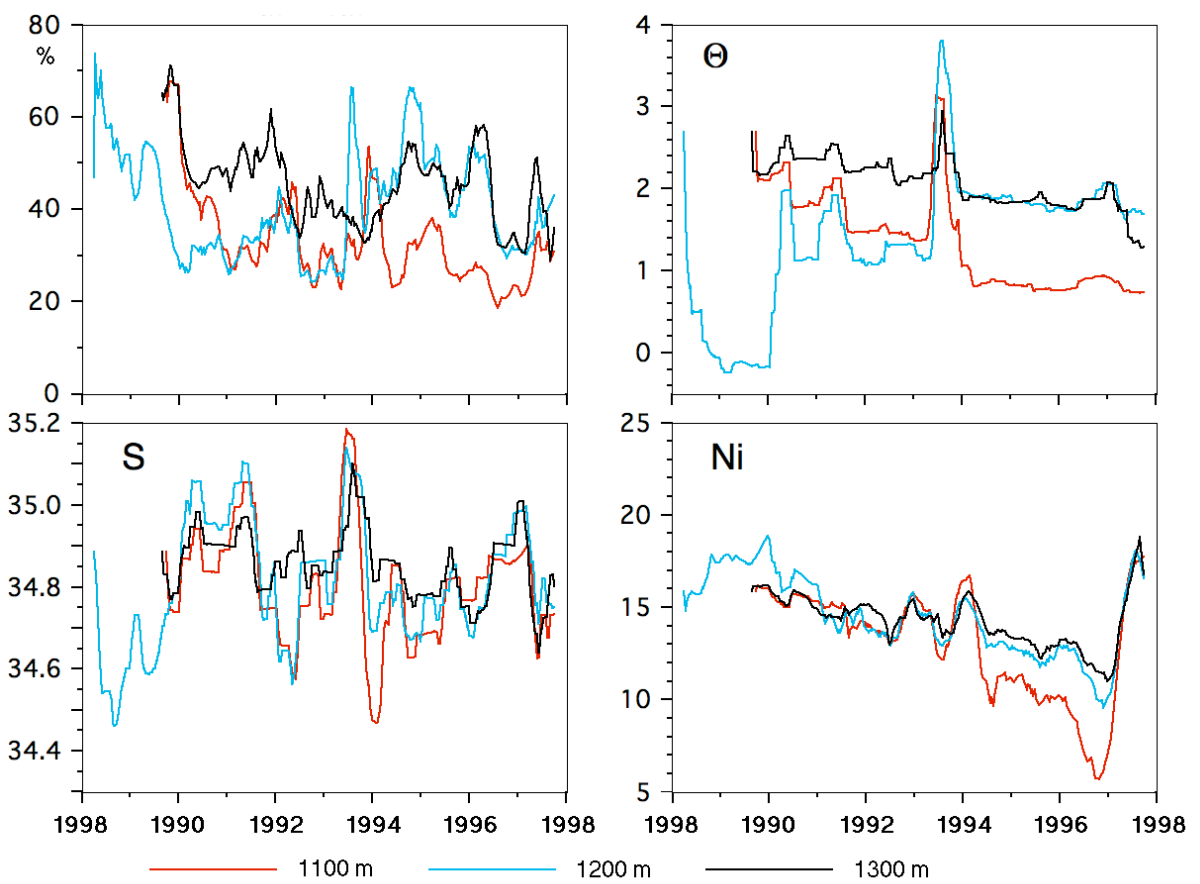

Fig. 6. Time development of the relative LSW contribution to the water samples and of the LSW source water properties potential temperature $\Theta\left({ }^{\circ} \mathrm{C}\right)$, salinity $\mathrm{S}$ and nitrate $\mathrm{Ni}(\mu \mathrm{mol} / \mathrm{L})$ if only LSW potential temperature, salinity and nitrate concentration are allowed to vary. Weights are taken from Leffanue and Tomczak (2004).

support for this assumption we performed a simple reduced major axis (Pearson, 1901) regression of the BATS data over the depth range $700 \mathrm{~m}-1600 \mathrm{~m}$ to determine the ratios of nitrate to phosphate and nitrate to silicate at the BATS station as functions of time. The results shown in Fig. 5 indicate significant variations in the nutrient ratios. Though it is possible to think of many reasons for the observed variations, the possibility that changes in the nitrate concentration of LSW may be responsible cannot be ruled out.

Figure 6 shows the final result of step 3 of the analysis (LSW potential temperature, salinity and nitrate concentrations defined as variables). It is seen that the relative water mass contributions remain relatively stable, starting at a slightly higher level before settling on the range 30-50\%. The largest LSW contribution is found at the $1300 \mathrm{~m}$ level, which should therefore be considered to give the most reliable result. Significant differences between solutions from different depth levels are observed as soon as the contribution of LSW falls below about $30 \%$. We conclude that TROMP analysis requires a minimum contribution of about $30 \%$ of a water mass if it is to give a physically realistic result. The only data set that satisfies this requirement for the entire observation period is the data set from the $1300 \mathrm{~m}$ depth level.

In contrast to the results of the runs of step 1, variations of LSW potential temperature and salinity in time are now comparable with the observations, and different depth levels 
often give identical results. Direct comparison requires an estimate of the transit time from the Labrador Sea to the BATS location. The calculated decrease of the potential temperature is about $0.6-1.0^{\circ} \mathrm{C}$, which compares well with the observed decrease of $0.9^{\circ} \mathrm{C}$ between 1970 and 1995 (Fig. 2). Transit times of the order of 6-10 years place the observed LSW potential temperature in the range $2.8-3.2^{\circ} \mathrm{C}$, slightly higher than derived by TROMP analysis. The LSW salinity in the range for the period is 34.83-34.88, somewhat lower than derived by TROMP analysis.

\section{Discussion}

The results presented in Fig. 6 show that it is possible to achieve reasonable agreement between observed and calculated time changes of LSW potential temperature and salinity by restricting the selection of variables to three LSW properties, namely potential temperature, salinity and nitrate. This does of course not imply that the source properties of all other water masses remained unchanged during the period. But the analysis suggests that of all possible variations in source water mass properties, the ones that had the greatest impact at the BATS location were the three properties identified through TROMP analysis. Many combinations of source water property changes can be imagined to explain the remaining difference between observed and calculated potential temperatures and salinities. Without additional information they would remain pure speculation.

Identifying the most appropriate solution to a nonlinear underdetermined system of equations is a complex task, and more work will be required to develop TROMP analysis into a standard technique of water mass analysis. The present paper has to be seen as a pilot project in that process. Future efforts will probably have to concentrate on methods to find the best weighting procedure, since the weights determine the search direction in parameter space for the minimization scheme and therefore have a large influence on the solution, as demonstrated through Figs. 3 and 4. The finally accepted solution (Fig. 6) displays similar or even larger ranges of time variability but opposite trends, with potential temperature and salinity both decreasing over time instead of increasing, which brings it much closer to the observed time development of LSW properties.

Reproducing observations through a highly underdetermined minimization technique does not add anything to the existing oceanographic knowledge unless it produces new insight in the process. The main result from this study is that knowledge of the time history of potential temperature and salinity in the Labrador Sea, combined with the knowledge of the time history of the complete suite of physical and nutrient data at the BATS location, provides strong evidence that the nitrate content of the Labrador Sea varied during the period, while oxygen and phosphate did not vary significantly. In our analysis the nitrate values for LSW show a clear trend, falling steadily from $16.1 \mu \mathrm{mol} / \mathrm{L}$ at the beginning of the analysis to $11 \mu \mathrm{mol} / \mathrm{L}$ towards the end but recovering to $18.7 \mu \mathrm{mol} / \mathrm{L}$ in the final six months. This corresponds approximately to the time when potential temperature and salinity began to diverge as deep convection in the Labrador Sea started to excavate the underlying North Atlantic Deep Water (Dickson et al., 1996).

The reasons for the change in LSW nitrate concentration are difficult to determine. Interannual variations in the convection depth can lead to changes in all water mass properties (the observed variations in temperature and salinity are generally attributed to that process). If NADW has a different Redfield ratio from the ratio found in the mixed layer, entrainment of NADW can result in a change of the LSW Redfield ratio; but it is unlikely that this leads only to a change in nitrate concentration and does not affect the other nutrients or oxygen. A more promising candidate for a satisfactory explanation would be a change in air-sea interaction processes, similar to those invoked by Hood et al. (2001) and Babiker et al. (2004). Our analysis can only serve as an incentive to look at long-term atmospheric conditions over the Labrador Sea and their impact on nutrient levels.

It is possible that the difference between observed and modelled potential temperature and salinity (Fig. 2 vs. Fig. 6) contains new insight as well. The observations that served to define the constraints for the model were taken by weather ship Bravo. The ship was located at approximately $56^{\circ} 30^{\prime} \mathrm{N}$ $51^{\circ} 00^{\prime} \mathrm{W}$, half way between the easternmost point of mainland Canada and the southern tip of Greenland. This places it in the centre of the Labrador Basin but on the southern border of the Labrador Sea proper, where the water mass formation occurs. It is possible that the LSW contribution at the BATS station was formed in the inner Labrador Sea. The observations taken at Bravo see LSW at the time of leaving the region, when it already had sufficient opportunity to be diluted and warm up from mixing. The result from TROMP analysis invites speculation that LSW at the source may have been colder and more saline than at weathership Bravo. While this cannot be verified in the current context it is comforting to note that the difference between observed and modelled potential temperature and salinity has the correct sign for such an interpretation.

Though originally developed for use in the analysis of oceanographic time series, TROMP analysis has several other potential applications. Tomczak and Liefrink (2005) recently completed an OMP analysis of WOCE section SR03 between Tasmania and Antarctica, which produced five oceanographic sections across the Circumpolar Current between 1991 and 1996. They found a significant increase of the volume of Lower Circumpolar Deep Water at the expense of Upper Circumpolar Deep Water over the five year period and raised the question whether this could at least partly be an artefact produced by variations in the source water properties of the water masses found in the section. A repeat analysis using the TROMP technique indicates that for the 
data collected in 1994-1996 the residual error cannot be reduced any further by changing the source water type definitions, confirming the correct choice of source water types in the OMP analysis. Significant reductions of the residual error are possible for the years 1991 and 1993. TROMP analysis is currently being used to determine the most appropriate water type definitions for these years and to construct a time history of Antarctic water mass properties (Tomczak and Liefrink, $2006^{1}$ ).

Another possible application of TROMP analysis is the determination of variations in the Redfield ratios. Historically it was assumed that these ratios are constant. During the last two decades it became evident that the ratios are functions of space (Takahashi et al., 1985; Anderson and Sarmiento, 1994; Shaffer, 1996; Hupe and Karstensen, 2000). There is now evidence to suggest that they can vary not only from region to region but also in time (Pahlow and Riebesell, 2000). TROMP analysis could prove a useful tool for the identification of variations in Redfield ratios in space or time.

Edited by: J. M. Huthnance

\section{References}

Anderson, L. A. and Sarmiento, J. L.: Redfield ratios of remineralization determined by nutrient data analysis, Global Biogeochem. Cycles, 8, 65-80, 1994.

Anderson, T. and Pondaven, P.: Non-Redfield carbon and nitrogen cycling in the Sargasso Sea: pelagic imbalances and export flux, Deep-Sea Res., I, 50, 573-591, 2003.

Babiker, I., Mohamed, A., Komaki, K., Ohta, K., and Kato, K.: Temporal Variations in the Dissolved Nutrient Stocks in the Surface Water of the Western North Atlantic Ocean, J. Oceanogr., 60, 553-562, 2004.

Curry, R. and McCartney, M.: Labrador Sea Water Carries Northern Climate Signal South, Oceanus, 39, 2, 24-29, 1996.

Dickson, R., Lazier, J., Meincke, J., Rhines, P., and Swift, J.: LongTerm Coordinated Changes in the Convective Activity of the North Atlantic, Prog. Oceanogr., 38, 241-295, 1996.

\footnotetext{
${ }^{1}$ Tomczak, M. and Liefrink, S.: On Interannual Variations of Water Mass Properties in the Southern Ocean. J. Atmos. Ocean Sci., submitted, 2006.
}

DuRand, M., Olson, R., and Chisholm, S.: Phytoplankton population dynamics at the Bermuda Atlantic Time-series station in the Sargasso Sea, Deep-Sea Res., II, 48, 1983-2003, 2001.

Henry-Edwards, A. and Tomczak, M.: Remote Detection of water property changes from a time series of oceanographic data, Ocean Sci., 2, 11-18, 2006.

Hupe, A. and Karstensen, J.: Redfield stoichiometry in Arabian subsurface waters, Global Biogeochem. Cycles, 14, 357-372, 2000.

Joyce, T. and Robbins, P.: The Long Term Hydrographic Record at Bermuda, J. Climate, 9, 3, 3121-3131, 1996.

Hood, R., Bates, N., Capone, D., and Olson, D.: Modeling the effect of nitrogen fixation on carbon and nitrogen fluxes at BATS, Deep-Sea Res., II, 48, 1609-1648, 2001.

Leffanue, H. and Tomczak, M.: Using OMP Analysis to Observe Temporal Variability in Water Mass Distribution, J. Mar. Syst., 48, 3-14, 2004.

Pahlow, M. and Riebesell, U.: Temporal trends in deep ocean Redfield ratios, Science, 287, 831-833, 2000.

Pearson, K.: On lines and planes of closest fit to systems of points in space, Philosophical Magazine, 6, 559-572, 1901.

Shaffer, G.: Biogeochemical cycling in the global ocean 2, new production, Redfield ratios, and remineralization in the organic pump, J. Geophys. Res., 101, 3723-3745, 1996.

Steinberg, D., Carlson, C., Bates, N., Johnson, R., Michaels, A., and Knap, A.: Overview of the US JGOFS Bermuda Atlantic Time-series Study (BATS): a decade-scale look at ocean biology and biogeochemistry, Deep-Sea Res., 2, 48, 1405-1447, 2001.

Takahashi, T., Broecker, W. S., and Langer, S.: Redfield ratio based on chemical data from isopycnal surfaces, J. Geophys. Res., 90, 6907-6924, 1985.

Tomczak, M.: A multi-parameter extension of temperature/salinity diagram techniques for the analysis of non-isopycnal mixing, Prog. Oceanogr., 10, 147-171, 1981.

Tomczak, M. and Liefrink, S.: Interannual variations of water mass volumes in the Southern Ocean, J. Atmos. Ocean Sci., 10, 31-42, 2005. 